\title{
Uptake of triacylglycerol-rich lipoproteins of differing triacylglycerol molecular species and unsaponifiable content by liver cells
}

\author{
Javier S. Perona ${ }^{1}$, Michael Avella ${ }^{2}$, Kathleen M. Botham ${ }^{2}$ and Valentina Ruiz-Gutierrez ${ }^{1} *$ \\ ${ }^{1}$ Instituto de la Grasa (CSIC), Av. Padre Garcia Tejero, 4.41012 Seville, Spain \\ ${ }^{2}$ Royal Veterinary College. Royal College Street, London, NWI OTU, UK
}

(Received 10 June 2005 - Revised 1 December 2005 - Accepted 19 December 2005)

\begin{abstract}
The fatty acid composition of dietary oils can modulate the incorporation of triacylglycerol-rich lipoproteins (TRL) into hepatocytes, thus affecting the atherogenicity of these particles. However, nothing is known about the effect of the unsaponifiable fraction of the oils. In the present study, we evaluated the influence of these components on the uptake of TRL by rat primary hepatocytes. TRL were isolated from human serum after the intake of meals enriched in high-oleic sunflower oil (HOSO), virgin olive oil (VOO) or VOO enriched in its own unsaponifiable fraction (EVO). HOSO and HOSO-TRL differed from VOO and EVO and their corresponding TRL in the composition of triacylglycerol molecular species and of the unsaponifiable fraction. Furthermore, the increase in the unsaponifiable fraction of VOO led to changes in the triacylglycerol molecular species in the EVO-TRL. On incubation with hepatocytes, HOSO-TRL were taken up at a faster rate than VOO-TRL or EVO-TRL. In addition, in comparison to VOO-TRL, HOSO-TRL increased the expression of mRNA for the LDL receptor-related protein receptor, which plays an important role in the internalisation of remnant lipoproteins. EVO-TRL also increased LDL receptor-related protein mRNA expression in comparison with VOO-TRL, but this change was not accompanied by a rise in the uptake rate, suggesting that the unsaponifiable fraction of VOO may inhibit LDL receptor-related protein expression or activity post-transcriptionally. In conclusion, TRL from dietary oils with differing triacylglycerol molecular species and unsaponifiable fraction content are taken up by liver cells at different rates, and this may be important in the atherogenicity of these particles.
\end{abstract}

Liver: Olive oil: Triacylglycerol: Triacylglycerol-rich lipoprotein: Uptake

Triacylglycerol-rich lipoproteins (TRL) consist of chylomicrons, which are secreted by the small intestine after a fat load and contain apo B-48 as the structural protein, and VLDL, which originate in the liver and contain apo B-100. In addition, TRL also include chylomicron and VLDL remnant particles, which are partially depleted of triacylglycerols and enriched with cholesteryl esters compared with their parent lipoproteins. A relationship between TRL and atherosclerosis has been demonstrated, as the remnant particles can cross the endothelial barrier and enter into the vascular wall (Mamo \& Wheeler, 1994), where, without the need for prior oxidation, they can affect endothelial function (Grieve et al. 1998, 2000) and cause the receptor-mediated lipid accumulation in macrophages that leads to foam cell formation (Napolitano et al. 2003; Wilhelm \& Cooper, 2003; Batt et al. 2004).

The transformation of TRL into remnant particles is dependent upon triacylglycerol hydrolysis by lipoprotein lipase, which is attached to the surface of the vascular endothelium (Wang et al. 1992). The enzyme can differentiate between substrates and exhibits specificity with regard to fatty acid length chain and unsaturation (Wang et al. 1992; Sato et al.
2002). Therefore, the composition of TRL-triacylglycerol is decisive for the activity of lipoprotein lipase and the formation of TRL remnants. Yet TRL are not completely hydrolysed by lipoprotein lipase in the plasma, and when they are taken up by the liver, they may retain up to $50 \%$ of their initial content of triacylglycerol (Jansen \& Hulsmann, 1985).

The second key step in the process of TRL removal from the blood is the uptake of the particles by the liver. The hepatic uptake of TRL remnants is mediated by apo E, which facilitates direct uptake via the LDL receptor (LDLr) by endocytosis, or sequestration of the particles to the heparin sulphate proteoglycan surface of the cells. The sequestered particles can be subsequently internalised via the LDLr or via the LDLr-related protein (LRP) receptor, which is also dependent on the presence of sufficient amounts of apo E within the particle (Cooper, 1997; Rohlmann et al. 1998; Zeng et al. 1998). It has become clear in recent years that dietary fatty acids affect hepatic gene expression for these receptors (Lambert et al. 2001; Zheng et al. 2002).

Following the Seven Countries Study, virgin olive oil (VOO) consumption, characteristic of the Mediterranean diet, has been proposed as a healthy dietary standard because 
it is associated with a low rate of cardiovascular mortality (Keys et al. 1986). However, there seem to be differences between diets enriched with different MUFA sources. Indeed, VOO and high-oleic sunflower oil (HOSO) produce different effects on the magnitude and duration of postprandial triacylglycerolaemia in normolipidaemic subjects (Abia et al. 2001; Perona et al. 2004). Therefore, other factors, such as triacylglycerol species composition, minor fatty acids and non-fatty acid constituents (unsaponifiable fraction), rather than the content of oleic acid, might be responsible for the postprandial responses to VOO, and possibly for the effects of the TRL and their remnants formed when the oil is consumed in the diet. In this regard, we have recently reported that the unsaponifiable fraction of VOO, contained in circulating TRL, improves the balance between the vasoprotective and prothrombotic factors released by endothelial cells (Perona et al. 2004).

Thus, differences in both the triacylglycerol molecular species and the composition of the unsaponifiable fraction of VOO and HOSO might affect the hydrolysis and hepatic uptake of TRL remnants. By comparing the postprandial response to diets containing VOO, HOSO and VOO enriched in its unsaponifiable fraction (enriched virgin olive; EVO) in the present study, we aim to evaluate the influence of the triacylglycerol molecular species and the unsaponifiable fraction composition on the postprandial TRL composition and the uptake of TRL remnants by cultured primary rat hepatocytes.

\section{Methods}

\section{Dietary study}

Ten male volunteers aged $26.5 \pm 3.6$ years, with a BMI of 24.9 (SD 1.4) kg/m², participated in the study. The volunteers had a mean fasting plasma triacylglycerol concentration in the normal range $(1.1(\mathrm{SD} 0.2) \mathrm{mmol} / \mathrm{l})$ and did not suffer from any digestive or metabolic disease, as verified by medical history. The subjects gave their written, informed consent to a protocol approved by the Institutional Committee on Investigation in Humans (Hospital Universitario Virgen del Rocío, Seville, Spain).

The test meal consisted of one slice of brown bread ( $28 \mathrm{~g})$, $100 \mathrm{~g}$ plain pasta (cooked with $200 \mathrm{ml}$ water), $130 \mathrm{~g}$ tomato sauce and one skimmed yoghurt, providing $2102 \mathrm{~kJ}$ energy. HOSO, VOO or EVO oils $(70 \mathrm{~g})$ were supplied mixed with the tomato sauce (total energy $4523 \mathrm{~kJ}$ ). The enrichment of EVO was carried out by isolating the unsaponifiable fraction from VOO and adding it to another aliquot of VOO, to a final concentration of $2.4 \%(\mathrm{~m} / \mathrm{m})$. The fatty acid and triacylglycerol molecular species composition of the VOO (v. hojiblanca) (Hojiblanca, Antequera, Spain) and HOSO (purchased at the local market) used for the meals are shown in Tables 1 and 2. The unsaponifiable fraction of the oils was also analysed and is reported in Table 3.

Participants were asked to refrain from smoking and drinking during the day preceding the study, given the influence of these substances on lipid metabolism. During the course of the study, the participants were allowed to drink water and/or black coffee without sugar and undertook only light activities. A baseline fasting blood sample was collected into Vacutainer
Table 1. Fatty acid composition of virgin olive oil (VOO) and high-oleic sunflower oil (HOSO)

(Mean values with their standard errors for three determinations)

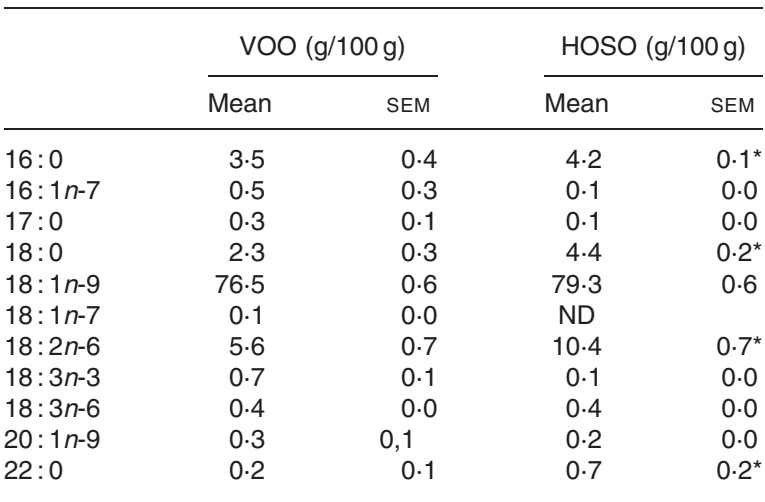

ND, not detected.

Mean values were significantly different from VOO; $P<0.05$

Table 2. Triacylglycerol molecular species composition of virgin olive oil (VOO) and high-oleic sunflower oil (HOSO)

(Mean values with their standard errors for three determinations)

\begin{tabular}{lccccc}
\hline & \multicolumn{2}{c}{ VOO $(\mathrm{g} / 100 \mathrm{~g})$} & & \multicolumn{2}{c}{ HOSO $(\mathrm{g} / 100 \mathrm{~g})$} \\
\cline { 2 - 3 } & Mean & SEM & & Mean & SEM \\
\cline { 2 - 3 } & 0.1 & 0.0 & & 3.0 & $0.7^{*}$ \\
LLL & 0.1 & 0.0 & & 4.0 & $1.8^{*}$ \\
OLL & 0.4 & 0.1 & & 0.6 & 0.1 \\
PLL & 6.7 & 0.2 & & 8.3 & 0.9 \\
OOL & 4.3 & 0.1 & & 2.0 & $0.2^{*}$ \\
POL/PoOO & 0.1 & 0.0 & & 0.1 & 0.0 \\
SLL & 0.1 & 0.1 & & ND & \\
PPL & 44.7 & 1.6 & & 63.8 & $4.7^{*}$ \\
OOO & 30.5 & 1.5 & & 7.8 & $1.3^{*}$ \\
POO & 2.5 & 0.1 & 2.7 & 0.2 \\
SOL & 3.3 & 0.2 & & 0.2 & $0.1^{*}$ \\
PPO & 0.1 & 0.0 & 0.3 & 0.1 \\
PPP & 5.3 & 0.1 & 5.8 & 0.3 \\
SOO & 1.0 & 0.5 & 1.1 & 0.4 \\
PSO & 0.2 & 0.0 & 0.2 & 0.0 \\
SSO & & &
\end{tabular}

ND, not detected.

Fatty acids: L, linoleic acid (18:2); O, oleic acid (18:1); Po, palmitoleic acid $(16: 1) ; P$, palmitic acid $(16: 0) ; S$, stearic acid $(18: 0)$.

Triacylglycerols: OOO, trioleoyl-glycerol; $\mathrm{POO}$, dipalmitoyl-oleoyl-glycerol

POL, palmitoyl-oleoyl-linoleoyl-glycerol.

Mean values were significantly different from VOO; ${ }^{*} P<0.05$.

Table 3. Unsaponifiable fraction composition of virgin olive oil (VOO) and high-oleic sunflower oil (HOSO)

(Mean values with their standard errors for three determinations)

\begin{tabular}{|c|c|c|c|c|}
\hline & \multicolumn{2}{|c|}{ VOO (mg/kg) } & \multicolumn{2}{|c|}{ HOSO (mg/kg) } \\
\hline & Mean & SEM & Mean & SEM \\
\hline Squalene & 6621 & 235 & ND & \\
\hline Total sterols & 1558 & 33 & 1497 & 54 \\
\hline Total tocopherols & 207 & 48 & 393 & $25^{\star}$ \\
\hline Erythrodiol + uvaol & $20 \cdot 98$ & 1.07 & ND & \\
\hline Waxes & 83.5 & $7 \cdot 9$ & $30 \cdot 0$ & $4 \cdot 8^{\star}$ \\
\hline
\end{tabular}

ND, not detected.

Mean values were significantly different from VOO; ${ }^{*} P<0.05$. 
tubes immediately before the subjects ate the test meal. Blood samples were drawn hourly during a $7 \mathrm{~h}$ postprandial period.

\section{Lipoprotein determination}

Serum was recovered rapidly by centrifugation $(3000 \mathrm{rpm}$, $\left.20 \mathrm{~min}, 12^{\circ} \mathrm{C}\right)$. NaAzide $(1 \mathrm{~mol} / \mathrm{l})$, phenylmethylsulfonyl fluoride $(10 \mathrm{mmol} / \mathrm{l}$ in isopropanol) and aprotinin $(1400 \mu \mathrm{g} / \mathrm{ml})$ were added to the plasma to a final concentration of $1 \mathrm{mmol} / \mathrm{l}$, $10 \mu \mathrm{mol} / \mathrm{l}$ and $28 \mu \mathrm{g} / \mathrm{ml}$ respectively. Serum total and HDLcholesterol and triacylglycerol concentrations were measured by conventional enzymatic methods. LDL-cholesterol concentration was calculated according to the Friedewald equation (Friedewald et al. 1972). TRL, collected $4 \mathrm{~h}$ after intake of the meal, were isolated from serum $(4 \mathrm{ml})$ layered with $6 \mathrm{ml} \mathrm{NaCl} \mathrm{sol-}$ ution (density $1.006 \mathrm{~g} / \mathrm{ml}$ ) by a single ultracentrifugation spin (40 $000 \mathrm{rpm}, 18 \mathrm{~h}, 15^{\circ} \mathrm{C}$ ). Ultracentrifugation was performed using a SW 41 Ti rotor in a Beckman L8-70M preparative ultracentrifuge (Beckman Instruments, Inc, Palo Alto, CA, USA).

\section{TRL lipid composition}

Total lipids were extracted from TRL following a modification of the method of Folch et al. (1957), using 2,6-di-tert-butyl-pcresol as antioxidant. The lipids extracted were redissolved in $1 \mathrm{ml}$ chloroform-methanol $(2: 1, \mathrm{v} / \mathrm{v})$ and preserved at under $-20^{\circ} \mathrm{C}$ until used. The composition by lipid class was determined by HPLC as described by Perona \& Ruiz-Gutierrez (2004).

In brief, $10 \mu \mathrm{l}$ lipids were dissolved in chloroformmethanol $(2: 1, \mathrm{v} / \mathrm{v})$ and injected by an automatic sampler into a 2690 Alliance liquid chromatograph (Waters, Milford, MA, USA) controlled by the Millennium 34 System (Waters). Detection was accomplished with a light-scattering detector (DDL31; Eurosep, Ins, Cergy-Pontoise, France). The separation of lipid classes was carried out on a Lichrosphere diol column $(250 \mathrm{~mm} \times 4.6 \mathrm{~mm}, 5 \mu \mathrm{m}$ particle size; Merck, Darmstadt, Germany) using a gradient-elution system containing hexane, 2-propanol and methanol. Stock solutions of cholesteryl oleate, triolein, oleic acid, cholesterol and phosphatidylcholine were prepared in chloroform-methanol $(2: 1, \mathrm{v} / \mathrm{v})$ and used as standard for identification and quantification of cholesteryl esters, triacylglycerol, NEFA, free cholesterol and phospholipids, respectively.

Triacylglycerols were analysed for their molecular species as previously described (Perona \& Ruiz-Gutiérrez, 1999). The chromatographic system consisted of a model 2690 Alliance liquid chromatograph (Waters), provided with a Spherisorb S3 ODS2 $(250 \mathrm{~mm} \times 4.6 \mathrm{~mm})$ of $3 \mu \mathrm{m}$ particle size (Waters). The liquid chromatograph was coupled to a lightscattering detector model 2420 (Waters). The system was controlled by computer through the Millenium 34 System (Waters). The mobile phase consisted of an initial elution gradient of $20 \%$ of acetone in acetonitrile, the percentage of acetone being raised to 45 in $12 \mathrm{~min}$ and then to 80 after $60 \mathrm{~min}$. This percentage was held until the end of the analysis. The flow rate was $1 \mathrm{ml} / \mathrm{min}$. Tripled runs of six concentrations of these standards (between 0.25 and $2.5 \mathrm{mg} / \mathrm{ml}$ in hexane; Sigma, St Louis, MO, USA)) were injected: tritridecanoin, 1,3-dioleoyl-2-palmitoyl-glycerol, trimyristin, 1,3-dioleoyl-2-stearoyl-glycerol, 1,3-dioleoyl-2- linoleoyl-glycerol, tripentadecanoin, tripalmitin, triolein and trilinolein. Various regression models were tested, and fourth regression curves $\left(r^{2} \geq 0.999\right)$ were finally chosen. Equations resulting from these curves were employed for quantification.

Triacylglycerols were transmethylated using sodium metoxide in methanol $(0.5 \%)$, and the resulting fatty acid methyl esters were analysed by GC, using a model 5890 series II gas chromatograph (Hewlett-Packard Co, Avondale, PA, USA) equipped with a flame ionisation detector and a capillary silica column Supelcowax 10 (Sulpelco Co, Bellefonte, PA, USA) of $60 \mathrm{~m}$ length and $0.25 \mathrm{~mm}$ internal diameter.

\section{Preparation and culture of hepatocytes}

Male Wistar rats (300-350 g body mass) were kept on a standard low-fat pellet diet, housed at constant day-length $(12 \mathrm{~h})$ and temperature $\left(25^{\circ} \mathrm{C}\right)$ and allowed access to food and water ad libitum. Hepatocytes were prepared from rat livers by perfusion with collagenase as previously described (Ford et al. 1985) and resuspended in RPMI 1640 medium supplemented with $\mathrm{NaHCO}_{3}(2 \mathrm{gl} / \mathrm{l})$, pyruvate $(110 \mathrm{mg} / \mathrm{l})$, dexamethasone $(1 \mu \mathrm{M})$, penicillin/streptomycin $(100 \mathrm{mg} / \mathrm{ml})$ and gentamicin $(50 \mathrm{mg} / \mathrm{l})$ (culture medium). Viable cells were then separated from non-viable cells using a Percoll gradient (Sigma Aldrich Chemical Co. Ltd., Poole, Dorset, UK) (0-70\%; Ford et al. 1985). The viable cells were washed twice with culture medium, resuspended in culture medium containing $10 \%(\mathrm{v} / \mathrm{v})$ fetal bovine serum and insulin $(4 \mathrm{mg} /$ $\mathrm{ml}$ ) and cultured in primaria-coated plastic dishes at $37^{\circ} \mathrm{C}$ in an atmosphere of $95 \%$ air $-5 \% \mathrm{CO}_{2}$ as described by Isusi et al. (2000). Cell viability, as assessed by Trypan blue exclusion, was greater than $90 \%$ in all experiments. After $2-3 \mathrm{~h}$ in culture, the cells adhered to the dishes, the medium and any non-adherent cells were removed, and culture medium containing $60 \mu \mathrm{g} / \mathrm{ml}$ insulin was added.

For TRL uptake experiments, TRL isolated from serum of the volunteers $4 \mathrm{~h}$ after the different test meals were labelled with the fluorescent probe 5-carboxytetramethyl rhodamine succimidyl ester (Cambridge Bioscience, Cambridge, UK) according to the manufacturer's instructions and added to the hepatocyte culture medium (final concentration $160 \mu \mathrm{g}$ triacylglycerol $/ \mathrm{ml}$ ). The dishes were then incubated for periods of up to $6 \mathrm{~h}$, and the cells were viewed with a LMS 510 laser-scanning confocal microscope (Carl Zeiss Ltd., Welwyn Garden City, Herts., UK). The fluorescence intensity per cell was quantified by absorbance volume analysis. The fluorescence for the whole field was assessed, the background deducted and the value obtained divided by the number of cells in the field. Two or three fields with an approximately equivalent number of cells were evaluated for each data point.

To determine the effect of the different types of TRL on mRNA expression for LDLr and LRP, the particles (final concentration $160 \mu \mathrm{g}$ triacylglycerol $/ \mathrm{ml}$ ) were incubated with hepatocytes for $5 \mathrm{~h}$, the medium was then removed, the cells were washed with PBS $(3 \times 1 \mathrm{ml})$, and the total RNA was extracted as described later.

\section{mRNA determination}

mRNA levels for LDLr and LRP were determined by RT-PCR. Total RNA was extracted from hepatocytes using 
a kit (Promega UK, Southampton, UK) according to the manufacturer's instructions. First-strand DNA synthesis was performed using avian myeloblastosis virus reverse transcriptase, and amplification was carried out using the following primers: LDLr, sense, GGAGAACTCTGTTCCGAGAGAA, antisense, GAGCTAGCTGCTTCTCATCCTC; LRP, sense, GAGGAGCCATTTCTCATCTTTG, antisense, ATGGTATCTCTGCCCTTGTCAC. Conditions were as follows: initial denaturation at $95^{\circ} \mathrm{C}$ for $15 \mathrm{~min}$, then 30 cycles consisting of denaturation at $94^{\circ} \mathrm{C}$ for $1 \mathrm{~min}$, annealing at $60^{\circ} \mathrm{C}$ (LDLr) or $56^{\circ} \mathrm{C}$ (LRP) for $1 \mathrm{~min}$ and extension at $72^{\circ} \mathrm{C}$ for $1 \mathrm{~min}$ (final extension at $72^{\circ} \mathrm{C}$ for $10 \mathrm{~min}$ ). The products (LDLr, 297 bp; LRP, 299 bp) were separated by electrophoresis using agarose gels $(1.2 \%$, w/v) containing ethidium bromide $(0.5 \mu \mathrm{g} / \mathrm{ml})$. The bands were quantified by optical density volume analysis and normalised using the values obtained simultaneously for glyceraldehyde-3-phosphate dehydrogenase in the samples. The linearity of the assay for each gene was established in preliminary experiments.

\section{Materials}

Collagenase, Percoll, antibiotics and insulin were obtained from Sigma-Aldrich Chemical Co Ltd (Poole, Dorset, UK). RPMI 1640 culture medium and fetal bovine serum were supplied by Invitrogen (Paisley, Renfrewshire, UK). Fetal bovine serum was heat inactivated at $56^{\circ} \mathrm{C}$ for $30 \mathrm{~min}$ before use.

\section{Results}

Fatty acid, triacylglycerol and unsaponifiable fraction composition of VOO and HOSO

Both oils had a similar amount of MUFA (79.6\% for HOSO and $77.4 \%$ for VOO), with oleic acid (18:1n-9) accounting for $99 \%$ of all MUFA (Table 1). Although VOO had a higher content of saturated fatty acid, owing to a higher percentage of palmitic $(16: 0)$ acid $(P=0 \cdot 001)$, the content of stearic acid $(18: 0)$ was higher in HOSO $(P=0 \cdot 001)$. In contrast, HOSO had a higher amount of linoleic acid $(18: 2 n-6$; $P=0.001)$. The fatty acid composition of EVO was the same as VOO, as this was not modified when supplemented with the unsaponifiable fraction (data not shown).

Although the main differences found in the fatty acid composition were reflected in the triacylglycerol molecular species composition, the content of stearic acid-containing triacylglycerol was similar in both oils (Table 2). VOO provided higher $(P<0.05)$ amounts of triacylglycerol-containing palmitic acid (palmitoyl-oleoyl-linoleoyl-glycerol, palmitoyl-dioleoylglycerol (POO) and dipalmitoyl-oleoyl-glycerol) to the experimental meals than did HOSO. Conversely, HOSO presented higher $(P<0.05)$ concentrations of triolein (trioleoyl-glycerol; OOO) and linoleic-acid rich triacylglycerol (trilinolein and oleoyl-dilinoleoyl-glycerol).

Squalene and erythrodiol were absent from the unsaponifiable fraction of HOSO but were present in high concentrations in VOO (Table 3). Also, the wax concentration was significantly higher in VOO $(P<0 \cdot 05)$. The sterol concentration did not differ between the oils. In contrast, the tocopherol concentration was higher in HOSO $(P=0.02)$. The unsaponifiable fraction composition of EVO was the same as that of VOO, but the total concentration was 2-fold higher (data not shown).

\section{Effect of VOO, EVO and HOSO on the lipid composition of TRL}

The VOO test meal resulted in a lower triacylglycerol concentration in TRL $4 \mathrm{~h}$ after intake $(P<0.05)$, which involved a concomitant increment in the relative concentrations of phospholipids $(P<0.05)$ compared with EVO and HOSO (Table 4). The concentrations of cholesteryl esters, free cholesterol and NEFA were similar in the TRL obtained after the three different test meals.

The most abundant triacylglycerol molecular species found in the TRL after feeding VOO and EVO was POO (Table 5). Although there was no difference in the triacylglycerol composition between these dietary oils, there were differences in the concentrations of two triacylglycerol moieties in TRL.

Table 4. Lipid class composition of triacylglycerol-rich lipoproteins collected $4 \mathrm{~h}$ after the intake of virgin olive oil (VOO), enriched virgin olive oil (EVO) or high-oleic sunflower oil (HOSO)

(Mean values with their standard errors for nine determinations)

\begin{tabular}{|c|c|c|c|c|c|c|}
\hline & \multicolumn{2}{|c|}{$\begin{array}{c}\text { VOO } \\
(\mathrm{g} / 100 \mathrm{~g})\end{array}$} & \multicolumn{2}{|c|}{$\begin{array}{c}\text { EVO } \\
(\mathrm{g} / 100 \mathrm{~g})\end{array}$} & \multicolumn{2}{|c|}{$\begin{array}{l}\text { HOSO } \\
(\mathrm{g} / 100 \mathrm{~g})\end{array}$} \\
\hline & Mean & SEM & Mean & SEM & Mean & SEM \\
\hline Cholesteryl esters & $12 \cdot 3$ & $1 \cdot 3$ & $11 \cdot 7$ & 1.4 & $12 \cdot 8$ & $1 \cdot 2$ \\
\hline Triacylglycerols & $55 \cdot 4$ & 4.7 & 68.4 & $2 \cdot 9^{*}$ & $66 \cdot 6$ & $3 \cdot 2^{*}$ \\
\hline NEFA & 1.3 & 0.2 & 0.9 & 0.2 & 1.4 & 0.2 \\
\hline Free cholesterol & $1 \cdot 1$ & 0.1 & 0.9 & $0 \cdot 1$ & 0.8 & 0.1 \\
\hline Phospholipids & $29 \cdot 9$ & 4.8 & $18 \cdot 1$ & $1 \cdot 7^{*}$ & $18 \cdot 4$ & $3.0^{*}$ \\
\hline
\end{tabular}

Mean values were significantly different from VOO; ${ }^{*} P<0.05$.

For details of procedures, see p. 890.

Table 5. Triacylglycerol molecular species composition of triacylglycerol-rich lipoproteins collected $4 \mathrm{~h}$ after the intake of virgin olive oil (VOO), enriched virgin olive oil (EVO) or high-oleic sunflower oil (HOSO)

(Mean values with their standard errors for nine determinations)

\begin{tabular}{|c|c|c|c|c|c|c|}
\hline & \multicolumn{2}{|c|}{ VOO (g/100 g) } & \multicolumn{2}{|c|}{ EVO $(\mathrm{g} / 100 \mathrm{~g})$} & \multicolumn{2}{|c|}{ HOSO (g/100 g) } \\
\hline & Mean & SEM & Mean & SEM & Mean & SEM \\
\hline OLL & $1 \cdot 11$ & 0.46 & 1.00 & 0.45 & $2 \cdot 44$ & $0.47^{\star \dagger}$ \\
\hline PLL & 5.63 & 2.94 & 5.85 & 3.88 & 4.67 & 2.55 \\
\hline PPoO & 0.87 & 0.35 & 0.74 & 0.37 & 1.00 & 0.56 \\
\hline $\mathrm{OOL}$ & $5 \cdot 65$ & 2.44 & $4 \cdot 31$ & $1 \cdot 15$ & 8.75 & $3 \cdot 23^{\star \dagger}$ \\
\hline POL & 14.74 & $2 \cdot 13$ & 14.49 & $2 \cdot 77$ & $16 \cdot 25$ & 5.46 \\
\hline PPL & $21 \cdot 16$ & 3.35 & 9.69 & $2.52^{*}$ & 29.09 & $7 \cdot 26^{\star \dagger}$ \\
\hline 000 & $17 \cdot 64$ & $4 \cdot 38$ & $27 \cdot 12$ & $5 \cdot 35^{*}$ & $10 \cdot 46$ & $4 \cdot 31^{\star \dagger}$ \\
\hline POO & $26 \cdot 34$ & 4.43 & 27.91 & $5 \cdot 01$ & $19 \cdot 68$ & $5 \cdot 96^{\star \dagger}$ \\
\hline PPO & 1.01 & 0.30 & 1.59 & 0.67 & 0.86 & $0.23^{\dagger}$ \\
\hline SOO & 3.59 & 0.55 & 3.40 & 1.48 & 4.02 & 1.84 \\
\hline POS & 1.09 & 0.38 & 1.49 & 0.47 & $1 \cdot 30$ & 0.58 \\
\hline Others & $1 \cdot 38$ & 0.38 & $2 \cdot 61$ & 0.67 & 2.02 & 0.52 \\
\hline
\end{tabular}

Fatty acids: L, linoleic acid $(18: 2)$; O, oleic acid $(18: 1)$; Po, palmitoleic acid (16:1); P, palmitic acid (16:0); S, stearic acid (18:0).

Triacylglycerols: OOO, trioleoyl-glycerol; POO, dipalmitoyl-oleoyl-glycerol; POL, palmitoyl-oleoyl-linoleoyl-glycerol.

Mean values were significantly different from VOO; $P<0.05$

Mean values were significantly different from EVO; $† P<0.05$

For details of procedures, see p. 890. 
Certainly, the concentration of OOO was higher $(P<0.05)$ in EVO, whereas that of dipalmitoyl-linoleoyl-glycerol (PPL) was higher in VOO. HOSO-derived TRL, however, showed more differences in triacylglycerol molecular species compared with VOO and EVO. These particles were rich in linoleic acid-containing triacylglycerol (oleoyl-dilinoleoyl-glycerol, dioleoyl-linoleoyl-glycerol and PPL; $P<0.05)$ and depleted in palmitic acid-containing triacylglycerol (POO and dipalmitoyl-oleoyl-glycerol; $P<0 \cdot 05$ ). Interestingly, in spite of the higher content in $\mathrm{OOO}$ in the parent oil, the concentration of this triacylglycerol was lower $(P<0.05)$ after the intake of HOSO compared with the other experimental dietary oils.

Only slight differences were found regarding the fatty acid composition among the TRL (Table 6). The content of palmitoleic (16:1n-9) and arachidonic $(20: 4 n-6)$ acids was higher in VOO- and HOSO-TRL than in EVO-TRL. However, no significant differences were observed for palmitic (16:0), oleic $(18: 1 n-9)$ and linoleic $(18: 2 n-6)$ acids.

\section{Effect of VOO, EVO and HOSO on TRL uptake by rat primary} hepatocytes

Fluorescence-labelled TRL derived from VOO, EVO or HOSO were incubated with cultured rat hepatocytes for 0.5 , 1,3 and $6 \mathrm{~h}$, and their uptake was assessed using confocal microscopy and quantified by volume density analysis. The results are shown in Figs 1 and 2. HOSO-derived TRL were incorporated into cells more rapidly and efficiently than those derived from the intake of $\mathrm{VOO}$ or EVO $(P=0.0039$ and $P=0.0042$, respectively). The curves were adjusted to hyperbolic curves, following the equation $\mathrm{y}=\mathrm{B}_{\max } \mathrm{x} \mathrm{X} /\left(\mathrm{K}_{\mathrm{d}}+\mathrm{X}\right)$, where $\mathrm{B}_{\max }$ is the maximum incorporation of TRL to the cells and $\mathrm{Kd}$ is the time at which half of the maximum incorporation was reached. All curves showed excellent fits, with $r^{2}$ values of 0.9722, 0.9836 and 0.9815 for HOSO, VOO and EVO, respectively.

Table 6. Triacylglycerol fatty acid composition of triacylglycerol-rich lipoproteins collected $4 \mathrm{~h}$ after the intake of virgin olive oil (VOO), enriched virgin olive oil (EVO) or high-oleic sunflower oil (HOSO)

(Mean values with their standard errors for nine determinations)

\begin{tabular}{|c|c|c|c|c|c|c|}
\hline & \multicolumn{2}{|c|}{ VOO (g/100 g) } & \multicolumn{2}{|c|}{ EVO (g/100 g) } & \multicolumn{2}{|c|}{ HOSO $(\mathrm{g} / 100 \mathrm{~g})$} \\
\hline & Mean & SEM & Mean & SEM & Mean & SEM \\
\hline $14: 1 n-5$ & ND & & 0.26 & 0.11 & 0.57 & 0.05 \\
\hline $16: 0$ & 18.45 & 1.94 & $18 \cdot 61$ & $2 \cdot 13$ & $19 \cdot 02$ & $3 \cdot 41$ \\
\hline $16: 1 n-9$ & $5 \cdot 38$ & $2 \cdot 32$ & 1.73 & $0.26^{*}$ & 4.01 & $1 \cdot 16^{\dagger}$ \\
\hline $16: 1 n-7$ & 1.46 & 0.31 & 1.78 & 0.43 & 1.37 & 0.05 \\
\hline $18: 0$ & 3.40 & 0.45 & $3 \cdot 22$ & 0.86 & $3 \cdot 32$ & 0.71 \\
\hline $18: 1 n-9$ & 44.75 & 2.67 & $47 \cdot 36$ & 4.44 & $45 \cdot 10$ & $6 \cdot 19$ \\
\hline $18: 1 n-7$ & 2.45 & 0.45 & 2.52 & 0.99 & 3.07 & 0.99 \\
\hline $18: 2 n-6$ & 19.29 & 1.35 & 18.99 & 1.97 & $20 \cdot 72$ & $4 \cdot 25$ \\
\hline $18: 3 n-6$ & ND & 0.31 & 0.07 & 0.18 & 0.09 & \\
\hline $20: 0$ & 0.91 & 0.38 & 0.99 & 0.10 & 0.82 & 0.13 \\
\hline $20: 1 n-9$ & 0.37 & 0.18 & 0.32 & 0.01 & 0.18 & $0.13^{*}$ \\
\hline $20: 2 n-6$ & 0.06 & 0.03 & 0.39 & $0.09^{*}$ & 0.70 & $0.45^{\star \dagger}$ \\
\hline $20: 3 n-6$ & 1.07 & 0.27 & $1 \cdot 21$ & 0.18 & 1.03 & 0.78 \\
\hline $20: 4 n-6$ & 1.42 & 0.23 & 0.86 & 0.48 & $1 \cdot 75$ & 0.89 \\
\hline $22: 0$ & 1.04 & 0.33 & 1.45 & 0.56 & 0.77 & $0.38^{\dagger}$ \\
\hline
\end{tabular}

Mean values were significantly different from VOO; ${ }^{*} P<0.05$. Mean values were significantly different from EVO; $† P<0.05$ For details of procedures, see p. 890.

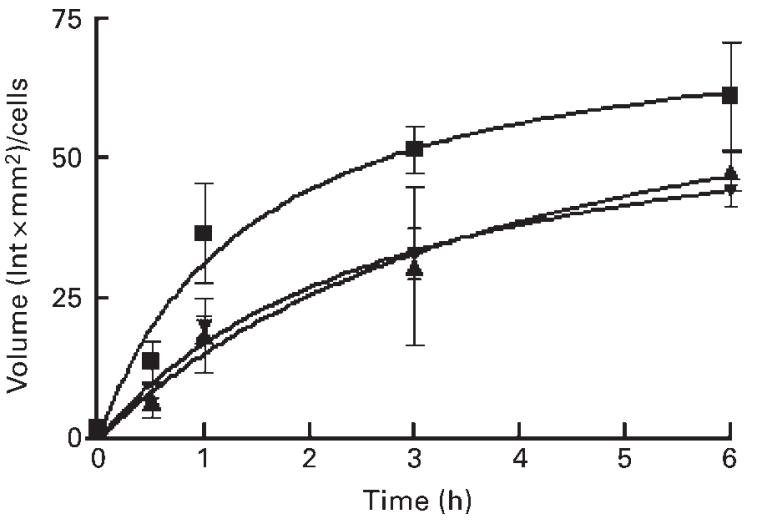

Fig. 1. Triacylglycerol-rich lipoprotein (TRL) internalisation by rat primary hepatocytes after incubation with TRL obtained $4 \mathrm{~h}$ after the intake of virgin olive $(\mathrm{VOO}, \boldsymbol{\square})$, enriched virgin olive $(\mathrm{EVO}, \mathbf{\nabla})$ and high-oleic sunflower $(\mathrm{HOSO}, \mathbf{\Lambda})$ oil $(n$ 9). TRL were labelled with the fluorescent probe 5-carboxytetramethyl rhodamine succimidyl ester, and the fluorescence viewed and measured by confocal microscopy.

Effect of VOO, EVO and HOSO on mRNA expression for the $L D L$ receptor and $L D L$ receptor-related protein

The mRNA expression for the receptors involved in TRL uptake by the hepatocytes is depicted in Fig. 3. The expression of LDLr was increased compared with controls (no TRL) when the cells where incubated with TRL originated from the intake of the three dietary oils tested. Although the expression of mRNA after the incubation with particles derived from the intake of EVO and HOSO was about $50 \%$ higher than that from VOO, the differences were not significant. There was also an increase in mRNA expression for LRP in hepatocytes incubated with TRL compared with control cells, although this was lower than that observed with the LDLr, and in this case there was also a significantly higher response with HOSO- and EVO-TRL compared with VOO-TRL $(P<0.05)$, with LRP mRNA expression being about $40 \%$ higher when the rat hepatocytes were incubated with EVO-TRL or HOSO-TRL rather than with VOO-TRL.

\section{Discussion}

We have previously shown that two dietary oils, VOO and HOSO, which have a similarly high content of oleic acid (77\% and $79 \%$, respectively; Table 1), with no other fatty acid making up more than $13.5 \%$ of the total, produce different effects on the magnitude and duration of postprandial triacylglycerolaemia in normolipidaemic subjects (Abia et al. 2001; Perona et al. 2004). We suggested, therefore, that triacylglycerol species composition, or non-fatty acid constituents (the unsaponifiable fraction), might be responsible for the postprandial response of VOO.

In the present study, we used three types of dietary oil to investigate the influence of the differences in triacylglycerol molecular species and unsaponifiable composition on the hepatic uptake of TRL. VOO was enriched with its own unsaponifiable fraction to obtain a final concentration of $2.4 \%(\mathrm{~m} / \mathrm{m})$. This strategy allowed us to compare two oils with exactly the same fatty acid and triacylglycerol molecular species composition and the same minor components but in an unusually high concentration. As we have used HOSO before to provide 

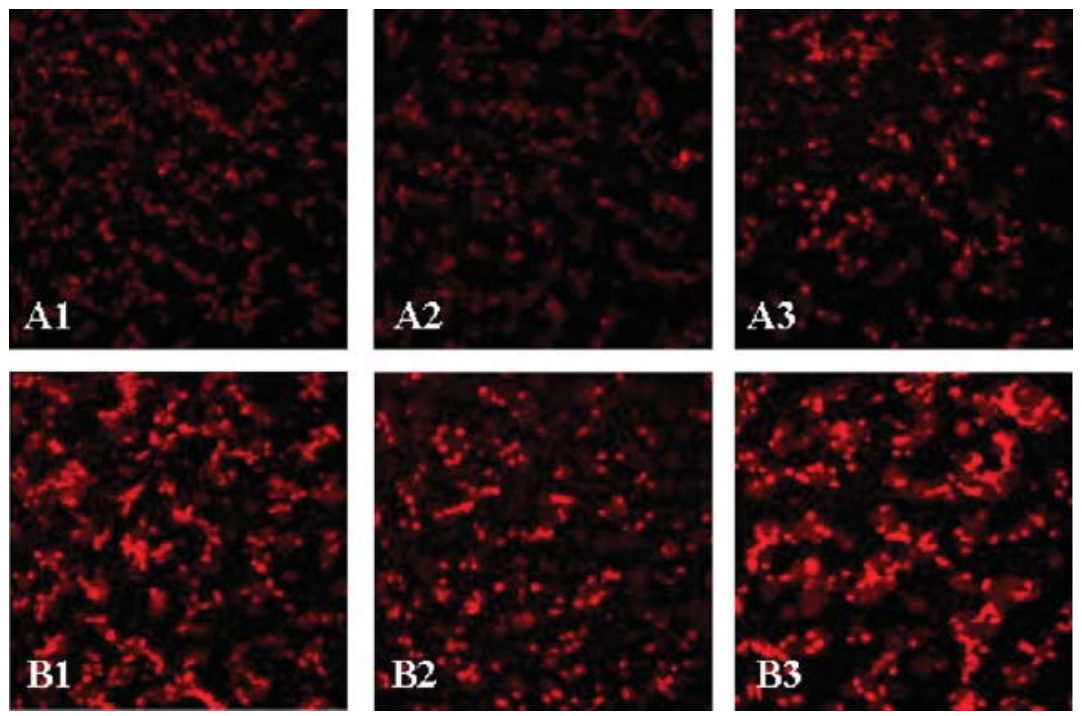

Fig. 2. Confocal microscopy images of primary rat hepatocytes after internalisation of triacylglycerol-rich lipoprotein (TRL) labelled with the fluorescent probe 5carboxytetramethyl rhodamine succimidyl ester. Hepatocytes were incubated for $1 \mathrm{~h}(\mathrm{~A})$ and $6 \mathrm{~h}(\mathrm{~B})$ with TRL obtained $4 \mathrm{~h}$ after the intake of virgin olive (VOO; 1 ), enriched virgin olive (EVO; 2) or high-oleic sunflower (HOSO; 3) oils. The images shown are from a typical experiment out of the nine performed.

oil differing from $\mathrm{VOO}$ in triacylglycerol molecular species, we included this oil in the study to investigate whether, in addition to the postprandial triacylglycerolaemia, VOO and HOSO would also elicit different effects on TRL uptake by the liver.

Increasing the unsaponifiable content of VOO altered the TRL lipid composition (Table 4). The triacylglycerol concentration of EVO was higher than that of VOO, whereas that of phospholipids was proportionally lower. We did not find this effect in TRL obtained $2 \mathrm{~h}$ after the intake of the same oils in our earlier study (Perona et al. 2004). We have previously reported that the maximum concentration of triacylglycerol after the intake of VOO or HOSO occurs about $2 \mathrm{~h}$ after intake in both plasma and TRL, whereas the lowest concentration occurs $4-5 \mathrm{~h}$ after intake (Abia et al. 1999, 2001; Perona et al. 2004). This triacyl-

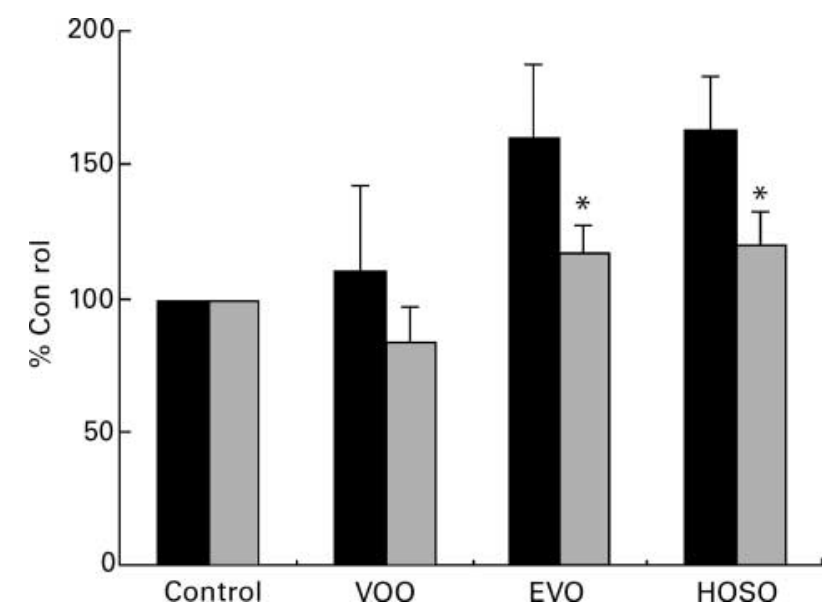

Fig. 3. mRNA expression for the LDL receptor (LDLr; $\square$ ) and LDL receptorrelated protein (LRP; $\square$ ) of rat primary hepatocytes after incubation with triacylglycerol-rich lipoproteins (TRL) obtained $4 \mathrm{~h}$ after the intake of virgin olive (VOO), enriched virgin olive (EVO) or high-oleic sunflower (HOSO) oil. Data are expressed as means and their standard errors $(n 9)$ as the percentage of the values obtained after incubating the cells in medium without TRL. Mean values were significantly different from VOO; ${ }^{\star} P<0.05$. glycerol depletion is concomitant with an increase in phospholipids, whereas cholesterol, either free or esterified, remains unchanged (Abia et al. 1999).

From these findings, we suggested that postprandial triacylglycerol secretion after the intake of VOO was mainly dependent upon triacylglycerol molecular species and not on the unsaponifiable fraction (Perona et al. 2004). However, one explanation for the results of the present study is that TRL formed from the two VOO with the same triacylglycerol molecular species composition but with varying concentrations of the unsaponifiable fraction are hydrolysed differentially, so that increasing levels of the fraction slow the rate of hydrolysis of the particles. Alternatively, it is possible that the unsaponifiable fraction affects the formation of chylomicrons in the intestine.

The lipid composition of TRL is dependent both on their formation in the small intestine, and on their rate of clearance from plasma, which occurs by two complementary mechanisms. First, triacylglycerols are hydrolysed by lipoprotein lipase (Wang et al. 1992), and then their remnants may be taken up by the liver (Cooper, 1997; Rohlmann et al. 1998; Zeng et al. 1998). The hydrolytic pathway of lipoprotein clearance is to a significant extent dependent on the triacylglycerol composition of TRL, owing to the specificity of lipoprotein lipase for different fatty acids and their stereospecific position in the glycerol backbone of the triacylglycerol (Botham et al. 1997). However, it has also been suggested that the polarity of the molecular species of the triacylglycerol in the TRL particle may affect its affinity for the enzyme (Sato et al. 1999).

In the present study, we observed some significant differences in the composition of the triacylglycerol moieties of TRL derived from VOO or EVO, with VOO-TRL containing significantly higher levels of PPL, but significantly lower levels of OOO (Table 5) suggesting that enrichment with the unsaponifiable fraction influences the molecular species incorporated into chylomicrons in the intestine. The triacylglycerol 
moieties of HOSO-TRL also showed significant changes compared with both VOO- and EVO-TRL, the main differences being a higher content of PPL and relatively lower levels of $\mathrm{OOO}$ and POO (Table 5). It seems likely that these differences are due to the quite large variations in the unsaponifiable fraction between HOSO and VOO (Table 3), rather than the relatively minor differences in their fatty acid compositions (Table 1). This is reinforced by the finding that there were only minor differences in the fatty acid composition of TRL-triacylglycerol (Table 6). These changes may influence the rate of clearance of the various types of TRL from the blood by increasing their rate of hydrolysis by lipoprotein lipase (Sato et al. 1999) and/or by increasing their rate of uptake by the liver. The lower content of triacylglycerol and higher level of phospholipids in VOO-TRL compared with EVO- and HOSO-TRL (Table 4) suggests that the VOO particles may be hydrolysed more rapidly, but the possibility that these changes are due to differences in chylomicron formation in the intestine cannot be ruled out.

Previous work has shown that the uptake of TRL by the liver is modulated by the fatty acid composition of the triacylglycerol in the particle (Ji et al. 1993; Bravo et al. 1995; Lambert et al. 1995), with TRL enriched in PUFA compared with saturated fatty acid being taken up faster, but nothing is known about the effects of the triacylglycerol molecular species or the content of the unsaponifiable fraction. The hepatic uptake of TRL remnants by the liver is mediated mainly by endocytosis via the LDLr and LRP, which recognise apo E in the particles (Cooper, 1997; Dietschy, 1998; Rohlmann et al. 1998). There may also be some uptake via a non-apo E-dependent pathway involving phospholipolysis (Borensztajn \& Kotlar, 1990; Crawford \& Borensztajn, 1999), but other possible routes of uptake such as the VLDL- and scavenger receptor B1 receptors do not appear to be involved (Vasandani et al. 2002).

In the present study, the rate of hepatic uptake of HOSO-TRL was significantly higher than that of TRL derived from EVO or VOO (Fig. 1). The type of fat in the diet has been shown to influence the activity of the LDLr (Dietschy, 1998), and evidence suggests that this involves changes in LDLr mRNA level (Nicolosi, 1997), although some studies have been unable to detect this effect (Spady et al. 1995). Zheng et al. (2002) have also reported that the expression of mRNA for LRP is downregulated in rat hepatocytes treated with remnant particles enriched with $n$-3 compared with $n-6$ PUFA. To investigate the mechanism underlying the differential rates of uptake of VOO-/EVO-TRL and HOSO-TRL, therefore, their effects on the expression of mRNA for LDLr and LRP were investigated. Interestingly, the expression of mRNA by primary rat hepatocytes for LRP was significantly lower when the cells were incubated with the TRL originated from the intake of VOO compared with both EVO- and HOSO-TRL (Fig. 3), and the LDL mRNA levels tended to be lower, although this effect did not reach significance. Thus, increasing the unsaponifiable fraction of VOO led to increased LRP transcription in response to TRL but did not result in a rise in uptake of the particles, although a similar increase in response to HOSO-TRL was associated with greater uptake. This suggests that the higher rate of uptake of HOSO-TRL cannot be explained by increased LRP expression, although it is possible that the higher levels of the unsaponifiable fraction in EVO may cause a post-transcriptional inhibition of protein expression or activity of the receptor, leading to a compensatory rise in mRNA levels.

The differential rate of uptake of remnant lipoproteins of different fatty acid composition by liver cells (Ji et al. 1993; Bravo et al. 1995; Lambert et al. 1995) has been found to be due mainly to differential interaction with the LDLr in hepatocytes from rats fed a low-fat diet, while both LDLr and LRP were involved in liver cells from rats fed high-fat diets (Lambert et al. 2001). Other work has also shown that the triacylglycerol molecular species in remnant lipoproteins influences their clearance from the blood (Redgrave et al. 1988). The reason for these differences is not known, but it has been suggested that it may be due to changes in the distribution and/or orientation of apoE on the surface of the particles (Redgrave et al. 1988; Lambert et al. 2001). Since no significant differences were found among the main fatty acids in TRL, the higher rate of uptake of HOSO-TRL in comparison to VOO- and EVO-TRL could be due to the different triacylglycerol molecular species in HOSO-TRL. The interaction of the particles with the LDLr or LRP might be changed by the higher content in PPL and lower content in POO and OOO in HOSO-TRL, compared with VOO and EVO-TRL. Alternatively, the difference in uptake rate between the three types of TRL might be related to content of the unsaponifiable fraction of HOSO.

In the present study, VOO and EVO were found to be much richer in squalene than $\mathrm{HOSO}$, and contained higher amounts of terpenoids (erythrodiol and uvaol) and waxes, whereas HOSO was higher than VOO, but not EVO, in tocopherols (Table 3). In previous work, the unsaponifiable fraction of VOO has been shown to have proatherogenic effects on processes such as inflammation in auricular oedema induced by 12-O-tetradecanoylphorbol-13-acetate (de la Puerta et al. 2000), rabbit LDL oxidation (Ochoa et al. 2002) and NO production by human endothelial cells (Perona et al. 2004). Both squalene and tocopherols potentially influence TRL uptake by the liver. The hepatic uptake of squalene, a cholesterol precursor, is associated with increased cholesterol synthesis, and Relas et al. (2000) have reported that a single dose of orally administered squalene increases cholesterol synthesis in human subjects. Increased cholesterol synthesis is associated with a downregulation of LDLr activity and may thus decrease TRL uptake (Pedersen et al. 2000). In addition, $\alpha$-tocopherol has been reported to upregulate mRNA expression and activity of the LDLr in the human liver cell line HepG2 (Pal et al. 2003). The higher rate of uptake of HOSO- compared with VOO- or EVO-TRL cannot, however, be explained by the tocopherol content, since the enrichment of the unsaponifiable fraction in EVO increases the level of tocopherols above that of $\mathrm{HOSO}$, but the relatively low content of squalene in HOSO compared with VOO and EVO may play a part. This is possible even though, in our experiments, LDLr mRNA levels were no lower with VOO- and EVO-TRL than with HOSO-TRL, since LDLr activity could be affected post-transcriptionally. For the moment, there are very few data available on the kinetics of the minor components of VOO and their incorporation into postprandial TRL, partly owing to the absence of specific methods for measuring these lipoproteins. This is a key issue that should be further investigated. 
In conclusion, the present study has demonstrated that TRL derived from three dietary oils with similar oleic acid content are metabolised differently. Enrichment of VOO with its unsaponifiable fraction changes the triacylglycerol molecular species formed in the intestine, decreasing the proportion of PPL and increasing that of OOO, and changes the lipid composition of TRL in the blood, raising the proportion of triacylglycerol and lowering that of phospholipids. Furthermore, the rate of uptake of TRL by hepatocytes was also affected. HOSOTRL were taken up at a faster rate than VOO- or EVO-TRL. This may be due to an upregulation of expression of mRNA for LRP, but may also involve changes in the triacylglycerol molecular species causing differential interaction with the receptors, and/or differences in the content of the unsaponifiable fraction between HOSO and VOO, particularly in terms of squalene. The unsaponifiable fraction of VOO, on the other hand, caused an increase in mRNA expression for LRP comparable to that seen with HOSO-TRL, but this did not result in an increased rate of uptake of the particles, suggesting that receptor protein expression or activity might be inhibited post-transcriptionally. These results indicate that triacylglycerol molecular species and the unsaponifiable fraction of dietary oils play a role in modulating the metabolism of TRL, and this may be important in the atherogenicity of these lipoprotein particles.

\section{Acknowledgements}

This work was supported by funds from Comision Interministerial de Ciencia y Tecnologia (CYCIT, AGL2002-00195), and AGL2005-00572), Fondo de Investigaciones Sanitarias (FIS. Red Corporativa ISCIII G03/140-2002) and a Juan de la Cierva contract to J. S. P.

\section{References}

Abia R, Pacheco YM, Perona JS, Montero E, Muriana FJ \& Ruiz-Gutierrez V (2001) The metabolic availability of dietary triacylglycerols from two high oleic oils during the postprandial period does not depend on the amount of oleic acid ingested by healthy men. J Nutr 131, 59-65.

Abia R, Perona JS, Pacheco YM, Montero E, Muriana FJ \& Ruiz-Gutierrez V (1999) Postprandial triacylglycerols from dietary virgin olive oil are selectively cleared in humans. J Nutr 129, 2184-2191.

Batt KV, Patel L, Botham KM \& Suckling KE (2004) Chylomicron remnants and oxidised low density lipoprotein have differential effects on the expression of mRNA for genes involved in human macrophage foam cell formation. J Mol Med 82, 449-458.

Borensztajn J \& Kotlar TJ (1990) Phospholipids as modulators of hepatic recognition of chylomicron remnants. Observations with emulsified lipoprotein lipids. Biochem J 269, 539-542.

Botham KM, Avella M, Cantafora A \& Bravo E (1997) The lipolysis of chylomicrons derived from different dietary fats by lipoprotein lipase in vitro. Biochim Biophys Acta 1349, 257-263.

Bravo E, Ortu G, Cantafora A, Lambert MS, Avella M, Mayes PA \& Botham KM (1995) Comparison of the hepatic uptake and processing of cholesterol from chylomicrons of different fatty acid composition in the rat in vivo. Biochim Biophys Acta 1258, 328-336.

Cooper AD (1997) Hepatic uptake of chylomicron remnants. J Lipid Res. 38, 2173-2192.

Crawford SE \& Borensztajn J (1999) Plasma clearance and liver uptake of chylomicron remnants generated by hepatic lipase lipolysis: evidence for a lactoferrin-sensitive and apolipoprotein E-independent pathway. J Lipid Res 40, 797-805. de la Puerta R, Martinez-Dominguez E \& Ruiz-Gutierrez V (2000) Effect of minor components of virgin olive oil on topical antiinflammatory assays. Z Naturforsch [C] 55, 814-819.

Dietschy JM (1998) Dietary fatty acids and the regulation of plasma low density lipoprotein cholesterol concentrations. J Nutr 128, 444S-448S

Folch J, Less M \& Sloan Stanley GH (1957) A simple method for the isolation and purification of total lipids from the animal tissues. J Biol Chem 33, 497-509.

Ford RP, Botham KM, Suckling RP \& Boyd GS (1985) Characterisation of rat hepatocyte monolayers for investigation of the metabolism of bile salts. Biochim Biophys Acta 836, 185-191.

Friedewald WT, Levy RI \& Fredrickson DS (1972) Estimation of the concentration of low-density lipoprotein cholesterol in plasma, without use of the preparative ultracentrifuge. Clin Chem 18, 499-502.

Grieve DJ, Avella MA, Botham KM \& Elliott J (2000) Chylomicron remnants potentiate phenylephrine-induced contractions of rat aorta by an endothelium-dependent mechanism. Atherosclerosis 151, 471-480.

Grieve DJ, Avella MA, Elliott J \& Botham KM (1998) The influence of chylomicron remnants on endothelial cell function in the isolated perfused rat aorta. Atherosclerosis 139, 273-281.

Isusi E, Aspicheta P, Liza M, Hernandez ML, Diaz C, Martinez MJ \& Ochoa B (2000) Short and long term effects of atrovastatin, lovastatin and simvastatin on the cellular metabolism of cholesteryl esters and VLDL secretion in rat hepatocytes. Atherosclerosis 153, 283-294.

Jansen H \& Hulsmann WC (1985) Enzymology and physiological role of hepatic lipase. Biochem Soc Trans 13, 24-26.

Ji Z-S, Fazio S, Lee YL \& Mahley RW (1993) Secretion-capture role for apolipoprotein $\mathrm{E}$ in remnant lipoprotein metabolism involving cell surface heparan sulfate proteoglycans. J Biol Chem 269, $2764-2772$.

Keys A, Menotti A, Karvonen MJ, et al. (1986) The diet and 15-year death rate in the seven countries study. Am J Epidemiol 124, 903-915.

Lambert MS, Avella MA, Berhane Y, Shervill E \& Botham KM (2001) The fatty acid composition of chylomicron remnants influences their binding and internalization by isolated hepatocytes. Eur J Biochem 268, 3983-3992.

Lambert MS, Botham KM \& Mayes PA (1995) Variations in composition of dietary fats affect hepatic uptake and metabolism of chylomicron remnants. Biochem J 310, 845-852.

Mamo JC \& Wheeler JR (1994) Chylomicrons or their remnants penetrate rabbit thoracic aorta as efficiently as do smaller macromolecules, including low-density lipoprotein, high-density lipoprotein, and albumin. Coron Artery Dis 5, 695-705.

Napolitano M, Avella M, Botham KM \& Bravo E (2003) Chylomicron remnant induction of lipid accumulation in J774 macrophages is associated with up-regulation of triacylglycerol synthesis which is not dependent on oxidation of the particles. Biochim Biophys Acta 1631, 255-264.

Nicolosi RJ (1997) Dietary fat saturation effects on low-density-lipoprotein concentrations and metabolism in various animal models. Am J Clin Nutr 65, Suppl., 1617S-1627S.

Ochoa JJ, Quiles JL, Ramirez-Tortosa MC, Mataix J \& Huertas JR (2002) Dietary oils high in oleic acid but with different unsaponifiable fraction contents have different effects in fatty acid composition and peroxidation in rabbit LDL. Nutrition 18, $60-65$.

Pal S, Thomson AM, Bottema CD \& Roach PD (2003) Alpha-tocopherol modulates the low density lipoprotein receptor of human HepG2 cells. Nutr J 2, 3 .

Pedersen A, Baumstark MW, Marckmann P, Gylling H \& Sandstrom B (2000) An olive oil-rich diet results in higher concentrations of LDL cholesterol and a higher number of LDL 
subfraction particles than rapeseed oil and sunflower oil diets. $J$ Lipid Res 41, 1901-1911.

Perona JS, Martinez-Gonzalez J, Sanchez-Dominguez JM, Badimon L \& Ruiz-Gutierrez V (2004) The unsaponifiable fraction of virgin olive oil in chylomicrons from men improves the balance between vasoprotective and prothrombotic factors released by endothelial cells. J Nutr 134, 3284-3289.

Perona JS \& Ruiz-Gutiérrez V (1999) Characterization of the triacylglycerol molecular species of fish oil by reversed-phase high-performance liquid chromatography. $J$ Liquid Chromatogr 22, $1699-1714$.

Perona JS \& Ruiz-Gutierrez V (2004) Quantification of major lipid classes in human triacylglycerol-rich lipoproteins by high-performance liquid chromatography with evaporative light-scattering detection. J Sep Sci 27, 653-659.

Redgrave TG, Kodali DR \& Small DM (1988) The effect of triacylsn-glycerol structure on the metabolism of chylomicrons and triacylglycerol emulsions in the rat. $J$ Biol Chem 263, 5118-5123.

Relas H, Gylling H \& Miettinen TA (2000) Dietary squalene increases cholesterol synthesis measured with serum non-cholesterol sterols after a single oral dose in humans. Atherosclerosis 152, 377-383.

Rohlmann A, Gotthardt M, Hammer RE \& Herz J (1998) Inducible inactivation of hepatic LRP gene by cre-mediated recombination confirms role of LRP in clearance of chylomicron remnants. $J$ Clin Invest 101, 689-695.

Sato K, Takahashi T, Takahashi Y, Shiono H \& Akiba Y (1999) Preparation of chylomicron and VLDL with monoacid-rich triacylglycerol and characterization of kinetic parameters in lipoprotein lipase-mediated hydrolysis in chickens. J Nutr $\mathbf{1 2 9}$, $126-131$.

Sato K, Takahashi Y, Takahashi T, Katoh N \& Akiba Y (2002) Identification of factors regulating lipoprotein lipase catalyzed hydrolysis in rats with the aid of monoacid-rich lipoprotein preparations. J Nutr Biochem 13, 528-538.

Spady DK, Horton JD \& Cuthbert JA (1995) Regulatory effects of n-3 polyunsaturated fatty acids on hepatic LDL uptake in the hamster and rat. J Lipid Res 36, 1009-1020.

Vasandani C, Kafrouni AI, Caronna A, Bashmakov Y, Gotthardt M, Horton JD \& Spady DK (2002) Upregulation of hepatic LDL transport by $\mathrm{n}-3$ fatty acids in LDL receptor knockout mice. J Lipid Res 43, 772-784.

Wang CS, Hartsuck J \& McConathy WJ (1992) Structure and functional properties of lipoprotein lipase. Biochim Biophys Acta $1123,1-17$.

Wilhelm MG \& Cooper AD (2003) Induction of atherosclerosis by human chylomicron remnants: a hypothesis. $J$ Atheroscler Thromb 10, 132-139.

Zeng BJ, Mortimer BC, Martins IJ, Seydel U \& Redgrave TG (1998) Chylomicron remnant uptake is regulated by the expression and function of heparan sulfate proteoglycan in hepatocytes. $J$ Lipid Res 39, 845-860.

Zheng X, Rivabene R, Cavallari C, Napolitano M, Avella M, Bravo E \& Botham KM (2002) The effects of chylomicron remnants enriched in n-3 or n- 6 polyunsaturated fatty acids on the transcription of genes regulating their uptake and metabolism by the liver: influence of cellular oxidative state. Free Radic Biol Med 32, $1123-1131$ 